\title{
Atypical imaging findings in a renal transplant patient with reversible posterior leukoencephalopathy syndrome: a case report Cristina Soler Riera*1, Leila Haddad ${ }^{1}$, Darío Scocco ${ }^{2}$, Gabriela Fischer ${ }^{3}$, Christian Lopez Saubidet ${ }^{1}$ and Paulino A Álvarez ${ }^{1}$
}

Address: ${ }^{1}$ Department of Internal Medicine, Centro de Educación Médica e Investigaciones Clínicas (CEMIC), Av Las Heras 2900 (C1425ASS), Buenos Aires, Argentina, 2 Department of Internal Medicine, Neurology Section, Centro de Educación Médica e Investigaciones Clínicas (CEMIC), Av Las Heras 2900 (C1425ASS), Buenos Aires, Argentina and ${ }^{3}$ Department of Internal Medicine, Nephrology Section, Centro de Educación Médica e Investigaciones Clínicas (CEMIC), Av Las Heras 2900 (C1425ASS), Buenos Aires, Argentina

Email: Cristina Soler Riera* - crisoler@telecentro.com.ar; Leila Haddad - hllh1@ hotmail.com; Darío Scocco - darioscocco@yahoo.com.ar; Gabriela Fischer - gfischersohn@gmail.com; Christian Lopez Saubidet - lopezsaubidet@hotmail.com;

Paulino A Álvarez - paulinoalvarez@hotmail.com

* Corresponding author

Published: 30 September 2009

Cases Journal 2009, 2:145 doi:10.1186/1757-1626-2-145

This article is available from: http://www.casesjournal.com/content/2/I//45

(C) 2009 Soler Riera et al; licensee BioMed Central Ltd.

This is an Open Access article distributed under the terms of the Creative Commons Attribution License (http://creativecommons.org/licenses/by/2.0), which permits unrestricted use, distribution, and reproduction in any medium, provided the original work is properly cited.

\begin{abstract}
Background: Atypical clinical and imaging findings in Reversible Posterior Leukoencephalopathy Syndrome are recognized with increasing frequency.

Case report: We report a case of an adult in his $5^{\text {th }}$ decade immunosupressed with methilprednisolone, tacrolimus and micophenolate who two months after renal transplantation, multiple infections and an episode of humoral rejection became hypertensive with severe headaches, visual field abnormalities, seizures, left hemiparesis and hemineglect.

Computed Tomography scan of the brain showed a hypo dense lesion in the left occipital lobe. Ischemic stroke was diagnosed and aspirin and permissive hypertension were indicated. Twelve hours later he developed left sided motor seizures and cortical blindness. Magnetic Resonance Image showed hyper intensity in T2 and FLAIR in both occipital lobes and a small area of cortical restricted diffusion in Diffuson Weighted Images in the left occipital lobe. With a diagnosis of Reversible Posterior Leukoencephalopathy Syndrome his blood pressure was controlled with intravenous labetalol, and two days later the neurologic findings returned to baseline and most Computed tomography findings resolved.

Conclusion: This case underscores that in the appropriate setting Reversible Posterior Leukoencephalopathy Syndrome should be suspected and the clinician should not be misled by atypical clinical or imaging findings. In contrast to other pathologies that resemble Reversible Posterior Leukoencephalopathy Syndrome, with the right and timely treatment, signs, symptoms and images can be completely reversible.
\end{abstract}

\section{Case Presentation}

A 44-year-old caucasian man underwent his second kidney transplantation. His induction regimen included thymoglobulin, methilprednisolone and rituximab. Because of increased risk of humoral rejection he underwent 5 plasmapheresis sessions before transplant. He was $1.6 \mathrm{~m}$ tall, and weighted $70 \mathrm{~kg}$. 
The maintenance immunosuppressive regimen included methilprednisolone, tacrolimus and micophenolate. Delayed graft function occurred and a renal biopsy done in the first week after transplant showed signs of probable humoral rejection. Gammaglobulin and plasmapheresis were started with mild improvement of renal function.

His medical history includes chronic renal failure secondary to focal and segmental glomerulonephritis, first renal transplantation 23 years before the present admission and on dialysis for the last 10 years, hepatitis $\mathrm{C}$ and left eye blindness of unknown etiology. He had no relevant family history and did not smoke or drink alcohol.

During first two months his post-transplant course was complicated by surgical wound infection, urinary fistula, nosocomial pneumonia due to Haemophilus influenzae, and abdominal wall abscess due to Acinetobacter baumanii.

One month after transplant the patient developed severe left sided headaches and blurred vision. He was hypertensive $(150 / 90 \mathrm{mmHg}$ with a usual blood pressure between 90-60 and 70-50) and a right temporal visual field deficit was detected. Computed Tomography (CT) showed a left occipital cortico-subcortical hypodense area. (Figure 1)

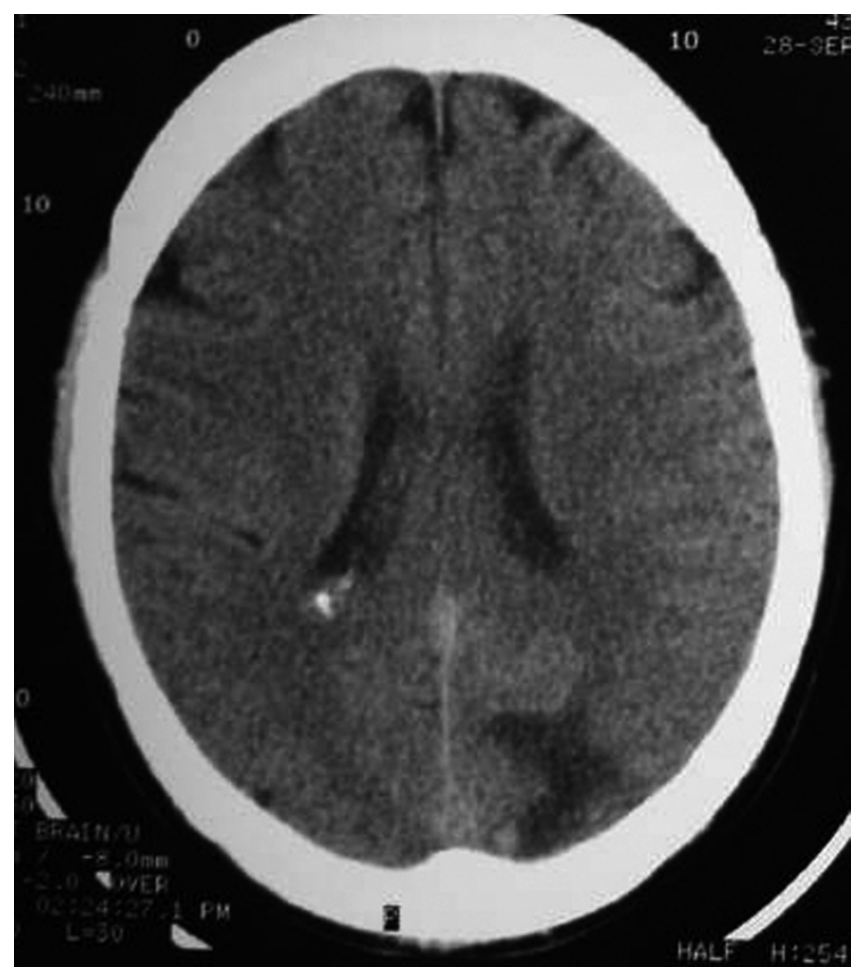

Figure I

Brain CT without contrast: left occipital cortico-subcortical hypodense area.
Serum creatinine was $3,79 \mathrm{mg} / \mathrm{dl}$, tacrolimus level was 6.8 (normal 5-20), platelets were $137.000 / \mathrm{ml}$. Other laboratory test results are shown in table 1.

A Neurology consultant suggested ischemic stroke as the cause, aspirin was started and permissive hypertension was allowed.

Twelve hours later he had an episode of left-sided motor focal seizures followed by left hemiparesis and was admitted to the intensive care unit. He was alert and oriented. Blood pressure was $165 / 71$, temperature $36.3^{\circ} \mathrm{C}$, heart rate 88 , pulse oximetry $100 \%$ on room air, respiratory rate 18. The neurological exam showed left arm and left leg weakness and bilateral amaurosis. A new CT scan showed bilateral occipital hypodensities and hemorrhagic foci. (Figure 2) Diphenilhydantoin was started. Brain Magnetic Resonance Image (MRI) showed bilateral occipital hyperintese lesions in Fluid Attenuated Inversion Recovery (FLAIR) and T2, a small area of cortical left occipital lobe restricted diffusion on Diffusion Weighted Image (DWI) and GRE sequence compatible with hemorrhage. (Figure $3,4,5,6)$ MRI venous and arterial angiography showed no abnormalities. (Figure 7,8)

With a diagnosis of Reversible Posterior Leukoencephalopathy Syndrome (RPLS) blood pressure was controlled with intravenous labetalol ( 2 doses of $10 \mathrm{mg}$ ). Neurologic findings including cortical blindness returned to normal within 48 hs.

A follow-up CT 17 days later showed decreasing hypodensity in left occipital and parietal lobes with improvement of the hemorrhagic foci and almost complete resolution of the right occipital lesions. (Figure 9)

\section{Discussion}

RPLS is a clinical radiologic syndrome of heterogeneous etiologies. In spite of its name the syndrome is not always reversible, and it is often not confined to either the white matter or the posterior regions of the brain [1]. Most common causes are hypertensive encephalopathy, ecclampsia, treatment with immunosuppressive agents or cytotoxic drugs and renal failure with hypertension. In solid organ transplantation the incidence of RPLS is low, between 0.49 and $6 \%[2]$.

Since the initial report in 1996 by Hinchey and coworkers the list of potential offending conditions have been increasing [3]. Although cyclosporine is the most common cytotoxic therapy associated with RPLS, it has been described with other agents including tacrolimus, sirolimus, cisplatin, interferon, and bevacizumab. 
Table I: Laboratory test results

\begin{tabular}{|c|c|c|c|c|c|}
\hline Variable & Reference range & $28-9-2008$ & $29-9-2008$ & $30-9-2008$ & $16-10-2008$ \\
\hline Hematocrit & $42-50 \%$ & 34 & & & 34 \\
\hline Hemoglobin & $14-17 \mathrm{~g} / \mathrm{dl}$ & 11 & & & 11.4 \\
\hline Platelets & $150000-300000 / \mathrm{ml}$ & 131000 & & & 131000 \\
\hline Leukocytes & $4000-10000 / \mathrm{ml}$ & 4800 & & & 6000 \\
\hline $\mathrm{Na}$ & $136-145 \mathrm{mEq} / \mathrm{L}$ & 136 & & & 138 \\
\hline K & $3.5-5.1 \mathrm{mEq} / \mathrm{L}$ & 5.5 & & & 4.7 \\
\hline Creatinine & $0.7-1.2 \mathrm{mg} / \mathrm{dl}$ & 3.79 & & & 3.25 \\
\hline BUN & $3.73-23.3 \mathrm{mg} / \mathrm{dl}$ & 76.44 & & & 96.94 \\
\hline Bilirrubin & $0.2-1.1 \mathrm{mg} / \mathrm{dl}$ & 0.7 & & & \\
\hline Total Protein & $6.4-8.3 \mathrm{gr} / \mathrm{dl}$ & 4.4 & & & \\
\hline Quick & $70-100 \%$ & $89 \%$ & & & \\
\hline APTT & $30-45 \mathrm{sec}$ & 33 & & & \\
\hline Calcium & $4.5-5.5 \mathrm{mEq} / \mathrm{L}$ & 3.8 & & & 4 \\
\hline TGP & $10-35 \mathrm{U} / \mathrm{L}$ & 14 & & & \\
\hline TGO & $10-40 \mathrm{U} / \mathrm{L}$ & 14 & & & \\
\hline $\mathrm{Ph}$ & 7.37-7.43 & 7.28 & & & 7.37 \\
\hline $\mathrm{pCO} 2$ & $35-45 \mathrm{mmHg}$ & 37 & & & 25 \\
\hline $\mathrm{HCO}-$ & 24-26 milimoles/I & 17.7 & & & 14 \\
\hline$M g$ & $1.6-2.5 \mathrm{mg} / \mathrm{dl}$ & & & 1.5 & \\
\hline Tacrolimus & 5-20 nanograms $/ \mathrm{ml}$ & & 6.8 & & \\
\hline
\end{tabular}

Among the many described causes of RPLS, hypertension, tacrolimus, immunoglobulin therapy and renal failure were present in our patient.

The pathogenesis of RPLS remains unclear, but it appears to be related to disordered cerebral autoregulation and endothelial dysfunction. Cytotoxic therapies have direct toxicity on vascular endothelium [1,3]. RPLS associated with these therapies may occur in normotensive individuals (although blood pressure is usually elevated over baseline), with nontoxic levels of these drugs, and it can happen even after several months of exposure to therapeutic levels $[1,3,4]$.
The combination of acute hypertension and endothelial damage results in hydrostatic edema. Hyperperfusion and edema is mainly seen in the posterior circulation, perhaps because there is a greater concentration of adrenergic nerves (thought to be responsible for cerebral autoregulation) around pial and intracerebral vessels in the anterior circulation than posteriorly.

Common clinical manifestations include headaches, altered consciousness, visual disturbances, and seizures.

The classic neuroimaging feature is edema involving the white matter in the posterior portions of the cerebral hem- 


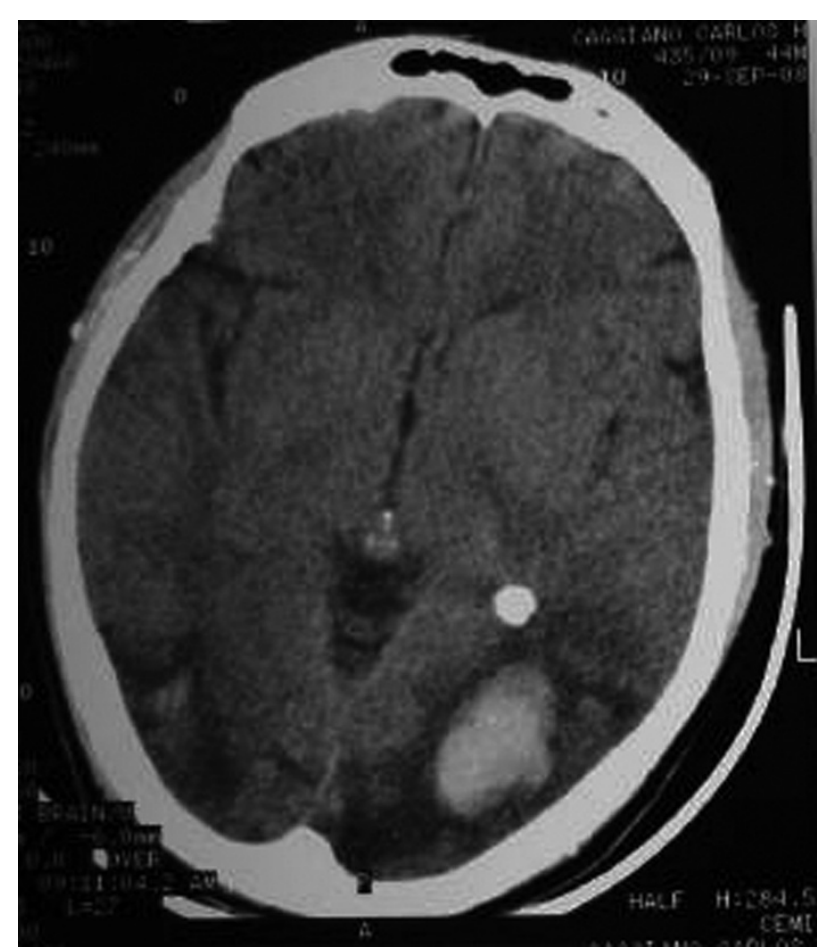

Figure 2

Brain CT without contrast bilateral occipital corticosubcortical hypodensities and hemorrhagic foci.

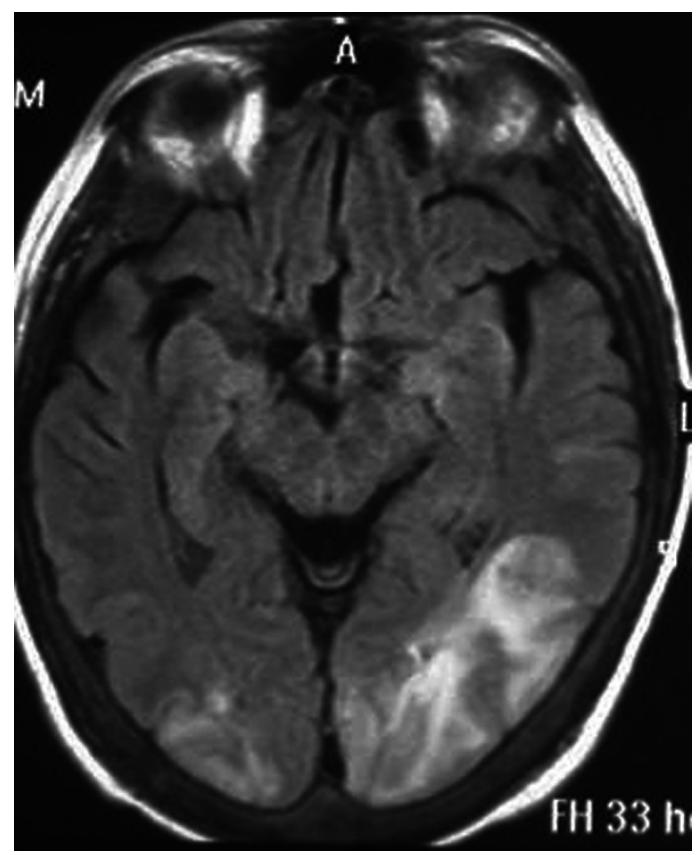

Figure 3

Brain MRI FLAIR Bilateral parieto-occipital hyperintese lesions.

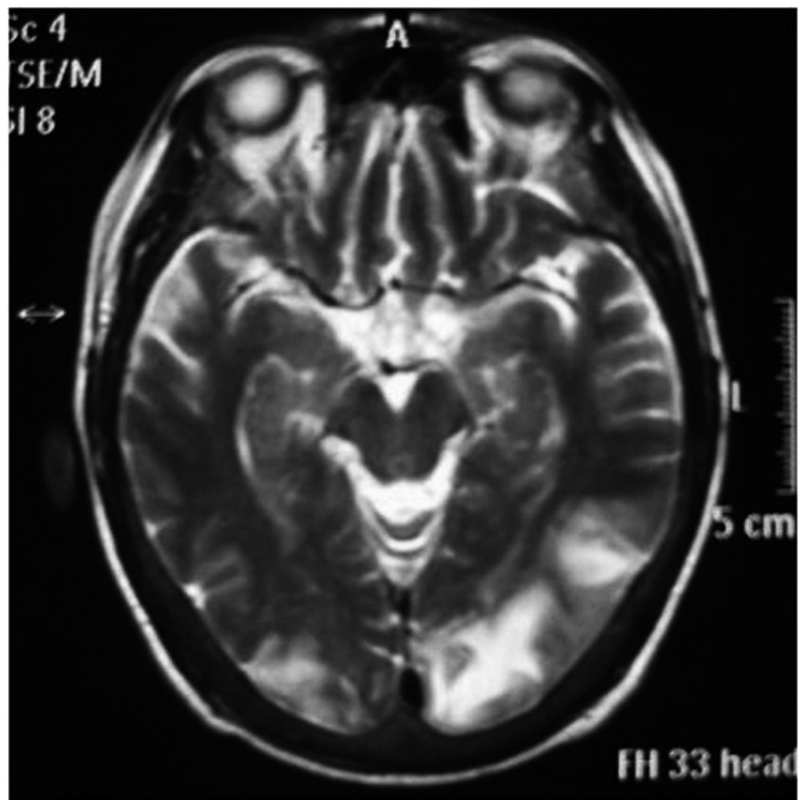

Figure 4

Brain MRI T2 Bilateral parieto-occipital hyperintese lesion.

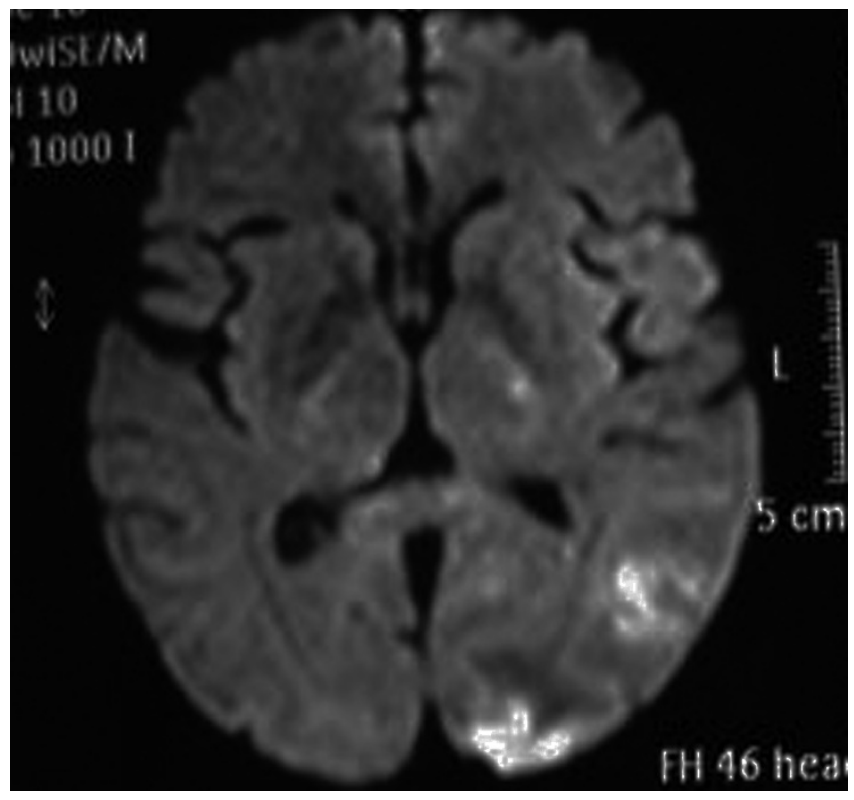

Figure 5

Brain MRI DWI: left occipital cortical restriction in DWI. 


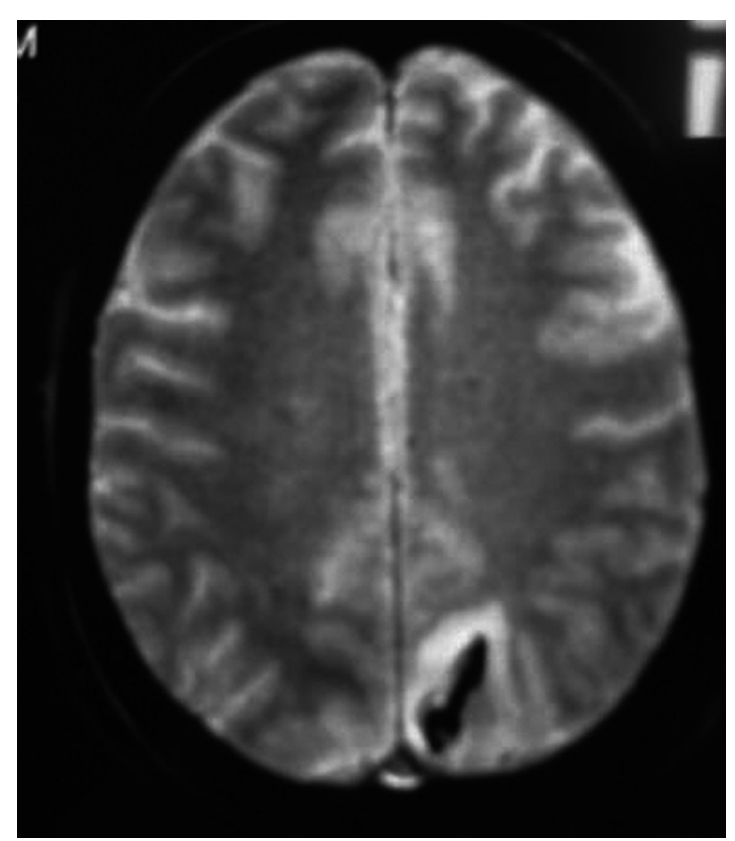

Figure 6

Brain MRI GRE: left subcortical parieto-occipital hemorragic foci.

ispheres, usually bilaterally in the parieto-occipital regions. The lesions are seen as white-matter hypodensities on CT scans and hypointense in T1, hyperintense in T2 and in FLAIR on MRI studies [5,6]. Atypical distributions and imaging manifestations such as significant anterior involvement, cortical lesions, recurrent RPLS episodes, foci of permanent injury, hemorrhage into lesions, unilaterality, and areas of restricted diffusion are

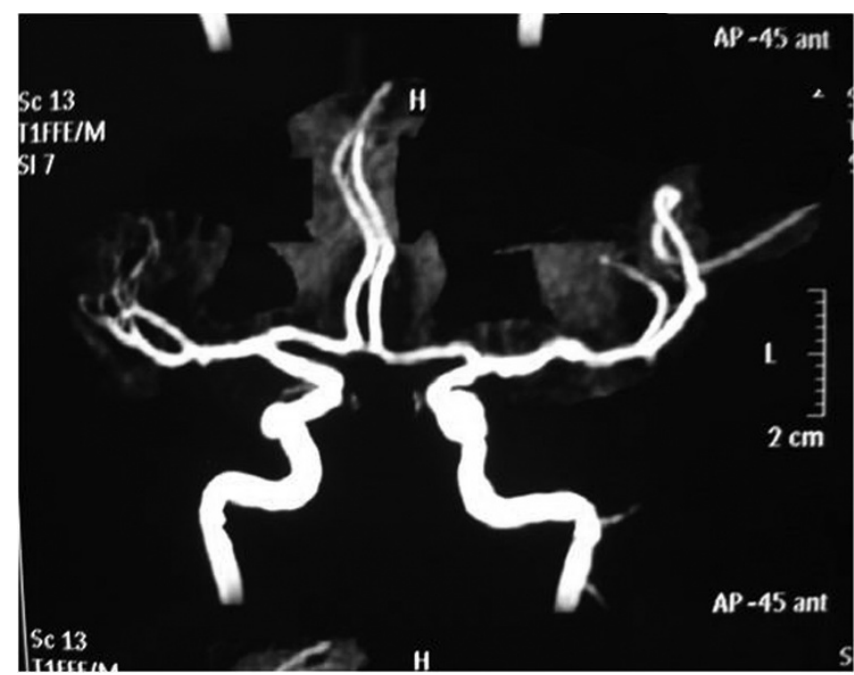

Figure 7

Brain MRI Angiography. Normal.
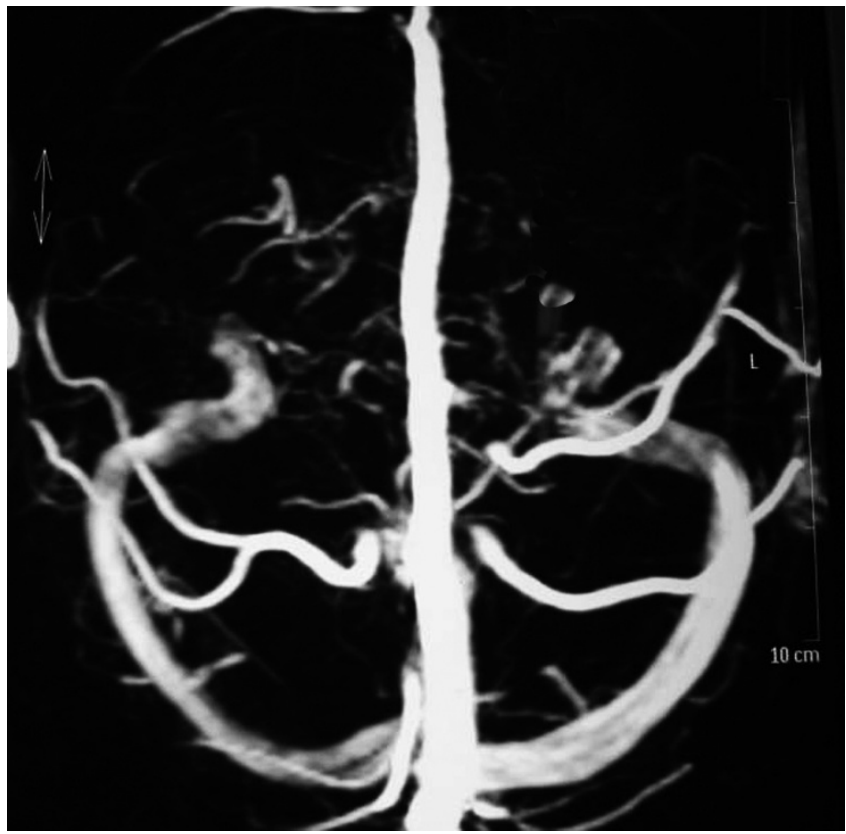

Figure 8

Brain MRI Venous Angiography. Normal.

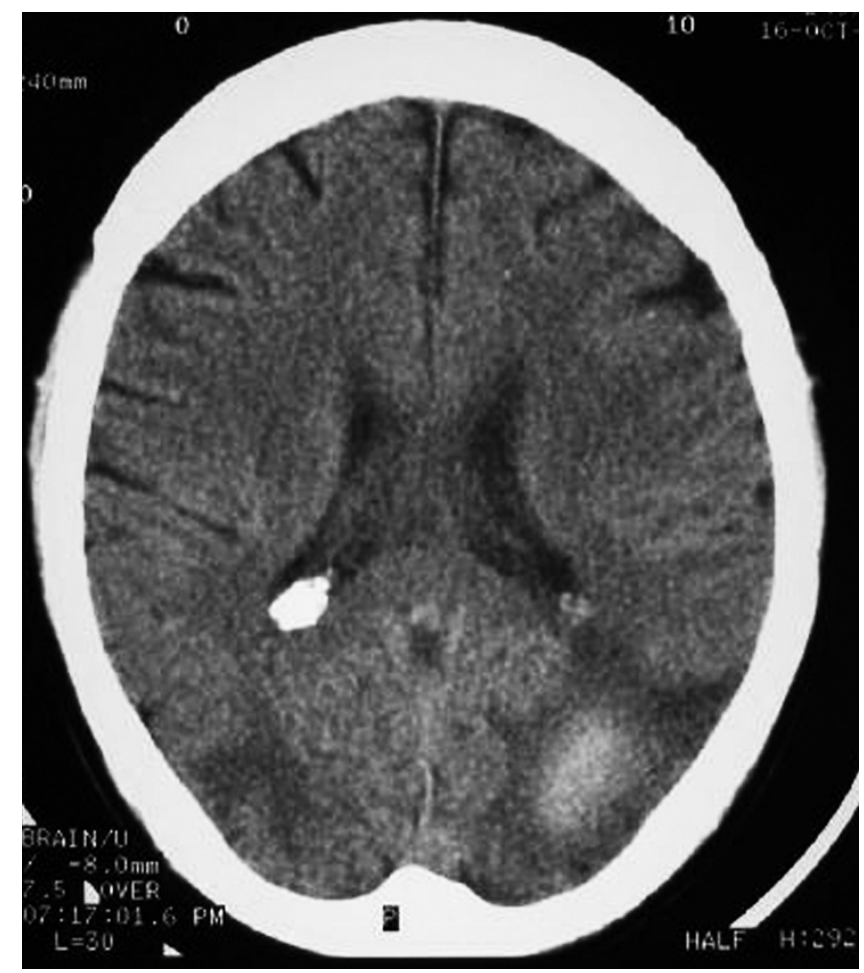

Figure 9

Brain CT without contrast. Decreasing hypodensity in left occipital and parietal lobes with improvement of hemorrhagic foci and almost complete resolution of right occipital lesions. 
described with increasing frequency in recent and larger series of patients $[7,8]$. Diffusion restriction in RPLS has been shown to occur in a minority of patients $(17 \%$ in a series) and usually is punctuate, small, or patchy and is surrounded by much larger areas of vasogenic edema $[8,6]$.

Differential diagnosis include stroke, venous thrombosis, toxic or metabolic encephalopathy, demyelinating disorders, vasculitis, and encephalitis among others. Particularly in cases with a sudden onset of neurologic symptoms, as was the case of our patient, the presentation can mimic bilateral posterior cerebral artery infarctions ("top of the basilar syndrome"). The fact that RPLS usually spares the calcarine and paramedian occipital lobe helps to differentiate these two entities [5]. This distinction is important because in RPLS hypertension should be treated in order to prevent permanent brain injury and blood pressure management in ischemic stroke remains controversial [9]. Furthermore RPLS patients should not receive antiplatelet treatment.

\section{Conclusion}

This reports calls attention to the fact that in the appropriate setting RPLS should be suspected and the clinician should not be misled by atypical clinical or imaging findings. In contrast to other pathologies that resemble RPLS, prompt recognition and treatment may prevent permanent damage.

\section{Consent}

Written informed consent was obtained from the patient for publication of this case report and accompanying images. A copy of the written consent is available for review by the Editor-in-Chief of this journal.

\section{Competing interests}

The authors declare that they have no competing interests.

\section{Authors' contributions}

PA, CS, CLS and LH analyzed and interpreted the patient clinical data and wrote the manuscript.DS and GF interpreted data regarding neurological and nephrological disease respectively. All authors read and approved the final manuscript.

\section{Acknowledgements}

The authors thank Juan Carlos Spina MD, for his contribution in the preparation of this manuscript.

\section{References}

I. Hinchey J, Chaves C, Appignani B, Breen J, Pao L, Wang A, Pessin MS, Lamy C. Mas JL, Caplan LR: A reversible posterior leukoencephalopathy syndrome. N Engl J Med I 996, 334(8):494-500.

2. Bartynski WS, Tan HP, Boardman JF, Shapiro R, Marsh JW: Posterior reversible encephalopathy syndrome after solid organ transplantation. AJNR Am J Neuroradiol 2008, 29(5):924-30.
3. Hinchey JA: Reversible posterior leukoencephalopathy syndrome: what have we learned in the last 10 years? Arch Neurol 2008, 65(2): : 75-6.

4. Bartynski WS: Posterior reversible encephalopathy syndrome, part 2: controversies surrounding pathophysiology of vasogenic edema. AJNR Am J Neuroradiol 2008, 29(6): I043-9.

5. Garg RK: Posterior leukoencephalopathy syndrome. Postgrad Med J 200I, 77(903):24-8.

6. Bartynski WS: Posterior reversible encephalopathy syndrome, part I: fundamental imaging and clinical features. AJNR Am J Neuroradiol 2008, 29(6): 1036-42.

7. Lee VH, Wijdicks EF, Manno EM, Rabinstein AA: Clinical spectrum of reversible posterior leukoencephalopathy syndrome. Arch Neurol 2008, 65(2):205-10.

8. McKinney AM, Short J, Truwit CL, McKinney ZJ, Kozak OS, SantaCruz KS, Teksam M: Posterior reversible encephalopathy syndrome: incidence of atypical regions of involvement and imaging findings. AJR Am J Roentgenol 2007, I 89(4):904-I2.

9. Adams HP Jr, del Zoppo G, Alberts MJ, Bhatt DL, Brass L, Furlan A, Grubb RL, Higashida RT, Jauch EC, Kidwell C, Lyden PD, Morgenstern LB, Qureshi AI, Rosenwasser RH, Scott PA, Wijdicks EF, American Heart Association; American Stroke Association Stroke Council; Clinical Cardiology Council; Cardiovascular Radiology and Intervention Council; Atherosclerotic Peripheral Vascular Disease and Quality of Care Outcomes in Research Interdisciplinary Working Groups: Guidelines for the early management of adults with ischemic stroke: a guideline from the American Heart Association/ American Stroke Association Stroke Council, Clinical Cardiology Council, Cardiovascular Radiology and Intervention Council, and the Atherosclerotic Peripheral Vascular Disease and Quality of Care Outcomes in Research Interdisciplinary Working Groups: the American Academy of Neurology affirms the value of this guideline as an educational tool for neurologists. Stroke 2007, 38(5): |655-7I I.
Publish with Bio Med Central and every scientist can read your work free of charge

"BioMed Central will be the most significant development for disseminating the results of biomedical research in our lifetime. " Sir Paul Nurse, Cancer Research UK

Your research papers will be:

- available free of charge to the entire biomedical community

- peer reviewed and published immediately upon acceptance

- cited in PubMed and archived on PubMed Central

- yours - you keep the copyright

Submit your manuscript here:

http://www.biomedcentral.com/info/publishing_adv.asp
BioMedcentral 